\title{
Lactation curve of Beetal goats in Pakistan
}

\author{
Abdul Waheed' and Muammad Sajjad Khan² \\ ${ }^{1}$ Faculty of Veterinary Sciences, Bahauddin Zakariya University, Multan, Pakistan, ${ }^{2}$ Department of Animal Breeding and \\ Genetics, University of Agriculture, Faisalabad, Pakistan
}

\begin{abstract}
This study was accomplished with the objective to determine parameters of lactation curves in Beetal goats using Wood's model. Therefore, milk yield data from 127 Beetal goats maintained at five different government farms were recorded from post-kidding to drying off of does. Wood model parameters were estimated using non-linear regression and individual curves were fitted. The characteristics/parameters of the lactation curve were computed. The mean initial yield »a «, rate of increase »b« and rate of decline »c« parameters in Wood's model for Beetal were $1214.97,0.3690$ and 0.1196 , respectively with $R^{2}$ value of $98.2 \%$. The value of percent squared bias and the persistency were 0.13 and $60.2 \%$, respectively with mean square error value of 38.45 . Flock effect was a significant $(P<0.01)$ source of variation for all the lactation curve parameters, percent squared bias and persistency. Parity did not affect significantly any of the parameters. Type of birth significantly influenced parameter »a«, Time to reach peak yield and lactation milk yield. Sex of kid also did not affect significantly any of the parameters. Age of doe was significant for parameters »a«, »b«, »c«. Quadratic effect of age was non-significant for all parameters and characteristics. Lactation length significantly affected parameter »a«, »b« and lactation milk yield.
\end{abstract}

Keywords: Beetal goats, lactation curve, Wood's model

Abbreviations: a: initial milk yield, b: rate of increase up to peak, c: rate of decline after peak, LL: length of lactation, LMY: lactation milk yield, MSE: mean square error, PSB: percent square bias, PY: peak yield, $\mathrm{R}^{2}$ : coefficient of determination, TPY: time to reach peak yield

Archiv Tierzucht 56 (2013) 89, 892-898

doi: 10.7482/0003-9438-56-089

Corresponding author:

Abdul Waheed; email: drabdulwaheed@bzu.edu.pk

Faculty of Veterinary Sciences, Bahauddin Zakariya University, Multan, Pakistan
Received: 19 November 2012

Accepted: 22 August 2013 Online: 23 August 2013

(C) 2013 by the authors; licensee Leibniz Institute for Farm Animal Biology (FBN), Dummerstorf, Germany. This is an Open Access article distributed under the terms and conditions of the Creative Commons Attribution 3.0 License (http://creativecommons.org/licenses/by/3.0/). 


\section{Introduction}

The term lactation curve is defined as graph between milk yield and length of time since kidding. The objective of modelling the lactation curve, generally, is to predict the milk production on each day with maximum precision to understand the underlying pattern of milk production in the presence of varying environment. Milk production in dairy goats typically inclines to a peak from the 4th to the 8th week postpartum and declines thereafter. A number of different empirical models have been developed to explain lactation curve (Gipson \& Grossman 1989, Wood 1974). Knowledge of this helps in prediction of total lactation milk yield from a single test day Wood (1974) or from several test days at the beginning of lactation and is a valuable tool for decision making in selection procedures.

Pakistan is one of the important goat producing countries in the world with current goat population of approximately 57 million heads (GOP 2008). Beetal goat is one among the reported 36 goat breeds by FAO in 2006, having great importance with a population of 4.2 million heads constituting $7.8 \%$ of the total goat population (GOP 2008) in the country. Beetal is also a preferred breed for sacrificial purposes such as »Eid ul Adha«.

Goats are hardy animals which can flourish well and rapidly in almost all regions of the world because they show well adaptability and greater tolerance for heat stress and resistance to diseases. Especially they thrive well in arid and desert conditions with minimum inputs. In addition, they are exceptionally prolific with greater ovulation rate, high fertility and conception rate. Their genetic efficiency and cost effective nature in converting scarce vegetation into good quality protein is an additional feature. There is a wide variation among breeds regarding their ability to produce milk.

A small number of studies are available on different aspects of different goat breeds in Pakistan. Genetic and phenotypic parameters for productive and reproductive traits of some goat breeds have been studied by some workers. The breeds studied were Teddy and Beetal. Growth curve of Beetal goats was characterized by Waheed et al. (2011) who also studied testicular biometry of Beetal male. Among many performance traits, milk production needs special emphasis if any of the breed is to be developed as dairy or dual purpose (meat \& milk) goat breed. Therefore, the present study was planned with the objectives to estimate characteristics of lactation curve in Beetal goats using non-linear regression models and to evaluate the environmental factors affecting these parameters.

\section{Material and methods}

\section{Source of data}

Weekly milk production records were measured for 127 Beetal goats from post-kidding to drying off of does, kept at Livestock Experiment Station Rakh Kheirewala, district Layyah $(n=30)$, Livestock Experiment Station Rakh Ghulaman, district Bhakkar $(n=20)$, Livestock Experiment Station Alladad, district Khanewal $(n=35)$, Livestock Production Research Institute, Bahadurnagar, district Okara $(n=35)$ and Livestock Experimental Station, University of Agriculture, Faisalabad ( $n=7$ ), Pakistan. The goats were allowed to graze from 08.00 to 17.00 daily without feeding any concentrates and were kept indoors at night. Kids were fed on milk in the morning and evening and weaned at 120 days of age. Information about 
pedigree, date of birth, date of kidding, type of birth and sex of kid (s) born were obtained from the registers maintained for management purposes.

Data comprised of 1862 test-day records on 127 Beetal does which were descendants of 27 sires and 64 dams.

Non-linear regression method was used for the estimation of parameters of lactation curves. For this purpose, Wood's model was fitted and parameters were computed using NLREG software Version 6.5 (Sherrod 2008; NLREG version 6.5, Brentwood, TN, USA). The following form of Wood's model was employed:

$$
Y_{t}=a t^{b} e^{(-c t)}
$$

where $Y_{t}$ is the observed test-day milk yield (litres), $a$ is the average initial yield, $b$ is the rate of increase up to peak, $c$ is the rate of decline after peak and $t$ is the time in weeks.

After fitting the model, parameters were estimated, the Wood's model parameters were used to draw lactation curve for Beetal goats to depict the shape of lactation curves.

The other characteristics of lactation curve were computed using following formulas Ali \& Schaeffer (1987):

$$
\begin{array}{ll}
\text { peak yield in } \mathrm{L}, & P Y=a\left(\frac{b}{c}\right)^{b} e^{-b} \\
\text { time to peak yield in weeks, } & T P Y=\frac{b}{c} \\
\text { percent squared bias, } & P S B=\frac{\Sigma\left(Y_{i j}-\hat{Y}_{i j}\right)^{2}}{\Sigma\left(Y_{i j}\right)^{2}}
\end{array}
$$

where $Y_{i j}$ is the observed milk yield $(L)$ and $\hat{Y}_{i j}$ is the predicted milk yield.

$$
\text { persistency }=100 \times \frac{T M Y_{L H}}{T M Y_{F H}}
$$

where $T M Y_{L H}$ is the cumulative milk yield of last half of lactation curve and $T M Y_{F H}$ is the cumulative milk yield of first half of lactation curve.

\section{Environmental factors}

To evaluate environmental factors affecting lactation curve characteristics, fixed effect model was used. The model included effect of flock, parity, type of birth and sex of kid(s) born. Age of doe and lactation length were used as (co)variables. The following models were assumed:

$$
Y_{i j k l m n o}=\mu+F_{i}+P_{j}+T O B_{k}+\operatorname{Sex}_{l}+b_{1}(\text { Age })_{m}+b_{2}(L L)_{n}+e_{i j k l m n o}
$$

where $Y_{i j k l m n o}$ is the estimated value of lactation curve parameters »a«, »b«, or »c«, $\mu$ is the mean value of the parameter, $F_{i}$ is the fixed effect of $i$-th flock, $P_{j}$ is the effect of $j$-th parity, $T O B_{k}$ is the effect of type of birth $(k=1,2,3)$, Sex, is the effect of sex of kid/s born, Age $e_{m}$ is the linear and quadratic effect of age of doe at kidding, $L L_{n}$ is the linear and quadratic effect of observed lactation length, $e_{i j k l m n o}$ is the random error associated with each observation, $b_{1}$ and $\mathrm{b}_{2}$ are regression coefficients.

ASReml version 2.0 (Gilmour et al. 2007; ASReml version 2.0. VSN International Ltd, Hemel Hempstead, HP1 1ES, UK) was used for evaluating the environmental factors affecting characteristics of lactation curves. 


\section{Results}

Estimates of different parameters and characteristics of lactation curves are given in Table 1. Changes in parameters in different parities are shown in Table 3. The lactation curves of the goats in different parities are drawn in Figure 1. Least squared means of different parameters for different lactation periods are presented in Table 4.

Table 1

Characteristics and other statistics of Wood's model for lactation curves in Beetal goats

\begin{tabular}{lclr}
\hline Parameters & Value \pm SE & Parameters & \\
\hline a (initial milk yield) & $1214.6 \pm 32.07$ & PY (peak yield) & 1.30 \\
b (rate of increase up to peak) & $0.3690 \pm 0.04$ & TPY (time to peak yield) & 3.10 \\
c (rate of decline after peak) & $0.1196 \pm 0.01$ & Persistency & 60.17 \\
& & R (coefficient of determination) & 0.98 \\
& & MSE (mean square error) & 38.45 \\
& & PSB (percent squared bias) & 0.13 \\
\hline
\end{tabular}

Table 2

Environmental factors affecting parameters and characteristics of lactation curve in Beetal goats

\begin{tabular}{|c|c|c|c|c|c|c|}
\hline \multirow[t]{2}{*}{ Parameter } & \multicolumn{5}{|c|}{ Environmental factors } & \multirow[b]{2}{*}{ LL } \\
\hline & Flock & Parity & Type of birth & Sex & Age & \\
\hline$a$ & $* * *$ & ns & ns & ns & ns & $* *$ \\
\hline b & $* * *$ & ns & ns & ns & $* * *$ & $* *$ \\
\hline c & $* * *$ & ns & ns & ns & $* * *$ & ns \\
\hline PY & $* * *$ & ns & ns & * & $* * *$ & ns \\
\hline TPY & $* * *$ & ns & ns & ns & ns & ns \\
\hline PSB & $* * *$ & $* *$ & ns & ns & ns & ns \\
\hline Persistency & $* * *$ & $* * *$ & ns & ns & ns & ns \\
\hline LMY & $*$ & ns & * & ns & ns & $* *$ \\
\hline
\end{tabular}

ns: not-significant, ${ }^{*} 0.05,{ }^{* *} 0.01,{ }^{* * *} 0.001$

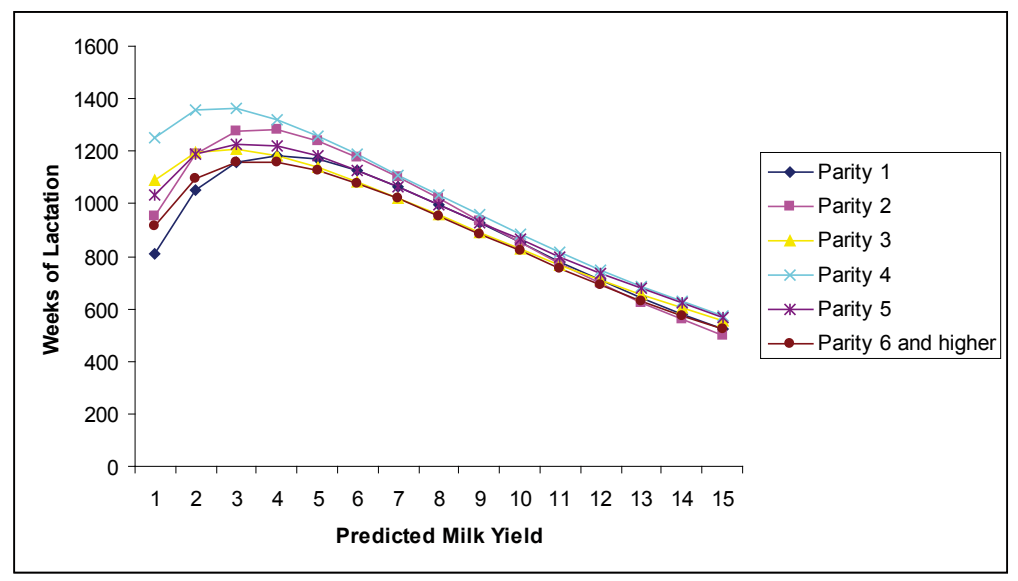

Figure 1

Lactation curves of Beetal goats in different parities 
Table 3

Parameters and characteristics of lactation curve for different parities in Beetal goats

\begin{tabular}{lccccccccc}
\hline Parity & $\mathrm{a}$ & $\mathrm{b}$ & $\mathrm{c}$ & MSE & $\mathrm{R}^{2}$ & PY & TPY & PSB & Persistency \\
\hline 1 & 546.5 & 0.5234 & 0.1059 & 61.8 & 0.94 & 747.3 & 5 & 0.2549 & 63.2 \\
2 & 1108.8 & 0.5359 & 0.1498 & 61.5 & 0.96 & 1284.6 & 4 & 0.2168 & 58.1 \\
3 & 1205.7 & 0.2856 & 0.1033 & 53.1 & 0.96 & 1211.6 & 3 & 0.2583 & 61.8 \\
4 & 1396.1 & 0.2733 & 0.1087 & 36.2 & 0.98 & 1366.6 & 3 & 0.0818 & 58.6 \\
5 & 1155.8 & 0.3644 & 0.1131 & 40.9 & 0.97 & 1229.6 & 3 & 0.1465 & 63.3 \\
$\geq 6$ & 1038.3 & 0.4416 & 0.1254 & 43.9 & 0.97 & 1164.0 & 4 & 0.1825 & 56.9 \\
\hline
\end{tabular}

Table 4

Least square means lactation curve constants derived from single factors fixed effect model for Beetal goats with different lactation lengths

\begin{tabular}{lcccc}
\hline Main effect & Groups & $\mathrm{a}$ & $\mathrm{b}$ & $\mathrm{c}$ \\
\hline Days & & $\mathrm{a} \pm$ SEa & $\mathrm{b} \pm$ SEb & $\mathrm{c} \pm$ SEc \\
$<90$ & 1 & $1172.1 \pm 108.50$ & $0.5761 \pm 0.1608$ & $0.1162 \pm 0.0260$ \\
$91-114$ & 2 & $1281.6 \pm 205.20$ & $0.6054 \pm 0.0511$ & $0.1584 \pm 0.0100$ \\
$115-124$ & 3 & $1301.7 \pm 160.90$ & $0.5277 \pm 0.0634$ & $0.1460 \pm 0.0119$ \\
$>125$ & 4 & & $0.1805 \pm 0.0552$ & $0.0714 \pm 0.0159$ \\
\hline
\end{tabular}

\section{Environmental factors affecting parameters and characteristics}

Flock effect was a significant source of variation for all parameters and characteristics. Flock significantly $(P<0.001)$ affected parameters and characteristics of lactation curve »a«, »b«, "C«, PY, TPY, PSB and persistency. Flocks had significantly $(P<0.05)$ different lactation milk yields. Peak yield and TPY did not differ among flocks. Lactation milk yield did not differ significantly among flocks and parities. Parity did not influence any of the characteristics of lactation curves except PSB $(P<0.001)$ and persistency $(P<0.05)$. The type of birth had no effect on lactation curve characteristics but only LMY was affected by it $(P<0.05)$, because twin producing does had higher LMY. Sex of kid/s born significantly $(P<0.05)$ affected PY only but it had had no effect on LMY. Linear effect of age of doe at time of kidding was a significant source of variation for $\gg b \ll, » c \ll$ and $P Y(P<0.001),(P<0.001)$ and $(P<0.001)$, respectively. Length of lactation (LL) had significant $(P<0.01)$ effect on »a« and »b« but PY, TPY, PSB, persistency and »c« were not affected by LL (Table 2).

\section{Correlations between parameters and characteristics}

Correlation between »a« and »b« parameters was moderate and negative in Beetal goats $(-0.27)$ but low positive correlations between »a« and »c« parameters $(0.13)$ and $» b \ll$ and »c« parameters (0.92) in this breed. Correlations between »a« and PY and »a and TPY were 0.87 and, -0.85 , respectively. Persistency and parameters were correlated negatively. The correlations between PY and TPY and PY and persistency were negative and high while TPY and persistency had positive correlations. All the correlations coefficients were statistically significant $(P<0.05)$. 


\section{Discussion}

Test day models are of great significance nowadays. Several models match differently the test day milk yields of goats. In the present study the classical Wood's gamma model was fitted to Beetal goat's lactation that already had shown best fit for lactation curves of other species and goat breeds. The parameter »a " which represents estimated milk yield post-kidding, was significantly higher for Beetal goats as estimated using incomplete gamma function (Wood's gamma model). The parameter »b « which was defined as rate of increase up to peak, was not much higher and showed that in Beetal goats milk yield increased sharply. Similarly the value of »c « for Beetal goats was lower, which showed slower decline in milk yield after peak. The Wood's gamma model had a good fit as depicted in the graph.

The estimated shapes of lactation curves of Beetal goats were similar with the shapes of observed lactation curves and the estimated curves fitted well during the whole lactation in contrast to Montaldo et al. (1997) who reported that the Wood's gamma model over predicted milk production during early and late lactation. Peak Yield in Beetal goats was higher than reported by Takma et al. (2009) and Akpa et al. (2001) but lower than other findings (Montaldo et al. 1997, Macciota et al. 2005).

The time to reach peak yield was lesser than reported by Montaldo et al. (1997) and Akpa et al. (2001) but longer than that reported by Takma et al. (2009) and Akpa et al. (2001) in different breeds of goats.

Coefficient of determination, $\mathrm{R}^{2}$, had high value. The result indicated that the proportion of error variance was small in total variances and thus happened to be good fit of the model to the data. The present values were similar to those found in available literature (Montaldo et al. 1997, Akpa et al. 2001) but slightly differed with others (Takma et al. 2009, Akpa et al. 2001). Percent square bias values for Beetal goats were much lower than estimated by Takma et al. (2009). Persistency values for Beetal goats were higher than those found by Takma et al. (2009). Mean square error values for this breed were much higher than results found by Takma et al. (2009).

The parameter »a« of lactation curve influenced by environmental factors as found in this study was in concordance with the findings of McManus et al. (2004) but differed for "b" and » « parameters, who reported that breed and type of kidding significantly affected the parameters. Age did not influence any of the parameters and the finding was similar to that of Dag et al. (2009). That characteristics of lactation curve were not affected by age, as found in this study, differed from results of others (Montaldo et al. 1997) who reported significant effect of age on the characteristics of lactation curve. Parity, in this study, was found to be non-significant source of variation for parameters and characteristics of lactation curve. On the contrary (Gipson \& Grossman 1990) reviewed that parity affected initial yield, time of maximum yield and persistency. Type of kidding had a significant effect on shape of lactation curve of Beetal goats in the present study. This fact opposed the findings of Portolano et al. (2009) who reported a non-significant effect of type of lambing on the shape.

Selection for parameter »a« may deteriorate parameter »b«, reduce time to reach peak yield, decline persistency but increase peak yield in Beetal goats because of high negative correlation. Some correlations found between the parameters of the model were quite low. The correlation between »a« and »c« parameter was low (0.13) as opposed to the highest 
correlation between these parameters reported by Gipson \& Grossman (1989) as 0.46 . Additionally, Morant \& Gnanasakthy (1989) pointed out that the highest correlation between »a« and any of the shape parameters was 0.37 . The high correlation between »b» and »c« (0.92) matched with the findings of Portolano et al. (1996) who reported it as 0.87 . In the present study, the correlation between parameters $» b$ « and »c« was found to be 0.92 and thereby much higher than reported by Gipson \& Grossman (1989).

The Wood's gamma model explained the variation quite accurately and described the shapes of lactation curves. The results can be used as a strategy tool to find out the optimum lactation length, milk production and peak milk yield, taking into account different number of parities. The better the understanding of lactation curve in goats, the more efficient the application of test day models for genetic evaluation and management decisions about milk production. An understanding of lactation curve would enable more efficient selection and management decisions, because a standard curve can provide a criterion for comparison for individual doe's milk production.

\section{References}

Akpa GN, Asiribo EO, Oni 0O, Alawa JP (2001) The influence of non-genetic factors on the shape of lactation curve in Red Sokoto goats. Anim Sci 72, 233-239

Ali TE, Schaeffer LR (1987) Accounting for covariances among test day milk yields in dairy cows. Can J Anim Sci 67, 637-644

Dag B, Keskin I, Mikailsoy F (2005) Application of different models to the lactation curves of unimproved Awassi ewes in Turkey. S Afr J Anim Sci 35, 238-243

Gilmour AR, Gogel BJ, Cullis BR, Welham SJ, Thompson R (2007) ASReml User Guide Release 2.0. VSN International Ltd, Hemel Hempstead, HP1 1ES, UK

Gipson TA, Grossman M (1989) Diphasic Analysis of Lactation Curves in Dairy Goats. J Dairy Sci 72, 1035-1044

Gipson TA, Grossman M (1990) Lactation curves in dairy goats: a review. Small Rumin Res 3, 383-396

GOP (Government of Pakistan) (2008) Economic Survey of Pakistan 2007-08. http://www.accountancy.com. pk/docs/economic-survey-pakistan-2007-08-02.pdf [last accessed 4.11.2013]

Macciota NPP, Fresi P, Usai G, Cappio-Borlino A (2005) Lactation curves of Sarda breed goats estimated with test day models. J Dairy Res 72, 470-475

McManus C, Filho GS, da Silva Mariante A, Louvandini H (2004) [Factors which influence parameters of goat lactation curves in the Federal District]. Rev Bras Zootec 32 (Suppl), 1614-1623 [in Portuguese]

Montaldo H, Almanza A, Juárez A (1997) Genetic group, age and season effects on lactation curve shape in goats. Small Rumin Res 24, 195-202

Morant SV, Gnanasakthy A (1989) A new approach to the mathematical formulation of lactation curves. Anim Prod 49, 151-162

Portolano B, Spatafora F, Bono G, Margiotta S, Todaro M, Ortoleva V, Leto G (1997) Application of the Wood model to lactation curves of Comisana sheep. Small Rumin Res 24, 7-13

Sherrod PH (2008) NLREG version 6.5. Brentwood, TN, USA http://www.nlreg.com [last accessed 4.11.2013]

Takma C, Akbas Y, Taskin T (2009) Modeling lactation curves of Turkish Saanen and Bornova goats. Asian J Anim Vet Adv 4, 122-129

Waheed A, Khan MS, Ali S, Sarwar M (2011) Estimation of growth curve parameters in Beetal goats. Arch Tierz $54,287-296$

Wood PDP (1974) A note on the estimation of total lactation yield from production on a single day. Anim Prod $19,393-396$ 